\title{
INFLUENCE OF GRAIN CROP PROPERTIES ON THEIR PROCESSING
}

\author{
Ramil Iskenderov, Anatoly Lebedev, Anton Zaharin, Roman Pavlyuk, \\ Pavel Lebedev, Nikolai Marin \\ Stavropol State Agrarian University, Russia \\ iskenderov_ramil@inbox.ru, lebedev.1962@mail.ru, \\ roman_pavlyuk_v@mail.ru, zoya_lebedeva@mail.ru
}

\begin{abstract}
Grain crops, after appropriate processing, are used as the main human food product, feed for farm animals and are raw materials for many industries (seed production, deep processing of grain, and others). For each specific direction, the corresponding machines and their complexes are used. The most important operation of grain processing is grinding. This process is accompanied by the formation of an over-grinded flour fraction and the presence in the finished product of intact, not destroyed, grains, which violates the particle size uniformity distribution up to $30 \ldots 40 \%$. The large particles are usually recycled, while the small ones are either removed from the process or processed on more sophisticated machines, such as extruders. All this leads to excessive consumption of energy, increased wear of the working bodies of machines and a decrease in the quality of the finished product. To increase the reliability and efficiency of the technological process, including grinding, we paid attention to such grain properties as its wear characteristics and the presence of macro and micro injuries. Our experimental analysis of "Yuka" wheat, "Atalis" corn, "Desant" oats and other grain crops showed that up to $24.6 \%$ of grains are damaged and may contain $4.7 \ldots 10 \%$ of mineral and trash impurities. These indicators are often ignored or considered insignificant, especially when preparing animal feed. But our experience showed that when grinding wheat grains with a concentration of abrasive particles of $0.4 . .5 .4 \%$ in a rotary grain crusher, the wear rate of the counterforce was $0.7 \ldots 2.8 \mathrm{~mm} \cdot \mathrm{t}^{-1}$. Due to the fact that forage crops initially have up to $30 \%$ injured grains, only one action of the working bodies during grinding is enough to obtain the required granulometric composition. The further development of these areas will reduce energy costs, increase the resource of machines and the quality of finished products of the grain processing industry.
\end{abstract}

Keywords: grain crops, operations of processing, grinding, quality, injury rate, mineral impurities, wear of working bodies.

\section{Introduction}

Grain crops are the main source of many of the world's food industries. The grains and beans of these crops are indispensable, affordable and highly nutritious components for the manufacture of many food products for humans and farm animals, as well as raw materials for seed production and deep processing. Grain processing, as a technological process, is accompanied by significant energy consumption and requires specialized machines (mills, crushers, roller mills, etc.) and operations (cleaning, washing, separation, etc.). According to various data [1], the destruction of the caryopsis requires $5 \ldots .40$ actions of the working bodies, for example, impacts in hammer crushers, which in practice leads to over-grinding of the total mass and the predominance of flour fractions in it. Even small violations and deviations from the technological standards (working clearance, rotation speed, wear of working bodies surfaces, etc.) during processing, as a rule, lead to a decrease in the quality of the finished product and reduce the efficiency of the grinder, extruder, conveyor, mixer or other machine used [1-3].

Figure 1 shows, developed by us, a scheme of the main pre and post processing operations of grain and legumes crops, which includes the industries where they are the main raw material.

The scheme shows that almost all types of industries are accompanied by grinding grain material. Modern grinders must be reliable and efficient, have a wide range of settings for the particle size of the finished product, and maintain an overall uniformity of particle size distribution up to $95 \%$. The key parameters affecting these characteristics are the working clearance and wear of the working surfaces $[4 ; 5]$.

Abrasive wear is present in all grinders, and the durability of working bodies can be increased due to reliable information about the mechanism of surface destruction in an abrasive environment. Our work confirms this, so, for example, in the working cavity of a rotary grain crusher, not only the smallest particles of the original product will act as an abrasive, but also mineral impurities that have got there in the mass of grain material and are on the surface of the grains $[6 ; 7]$. 


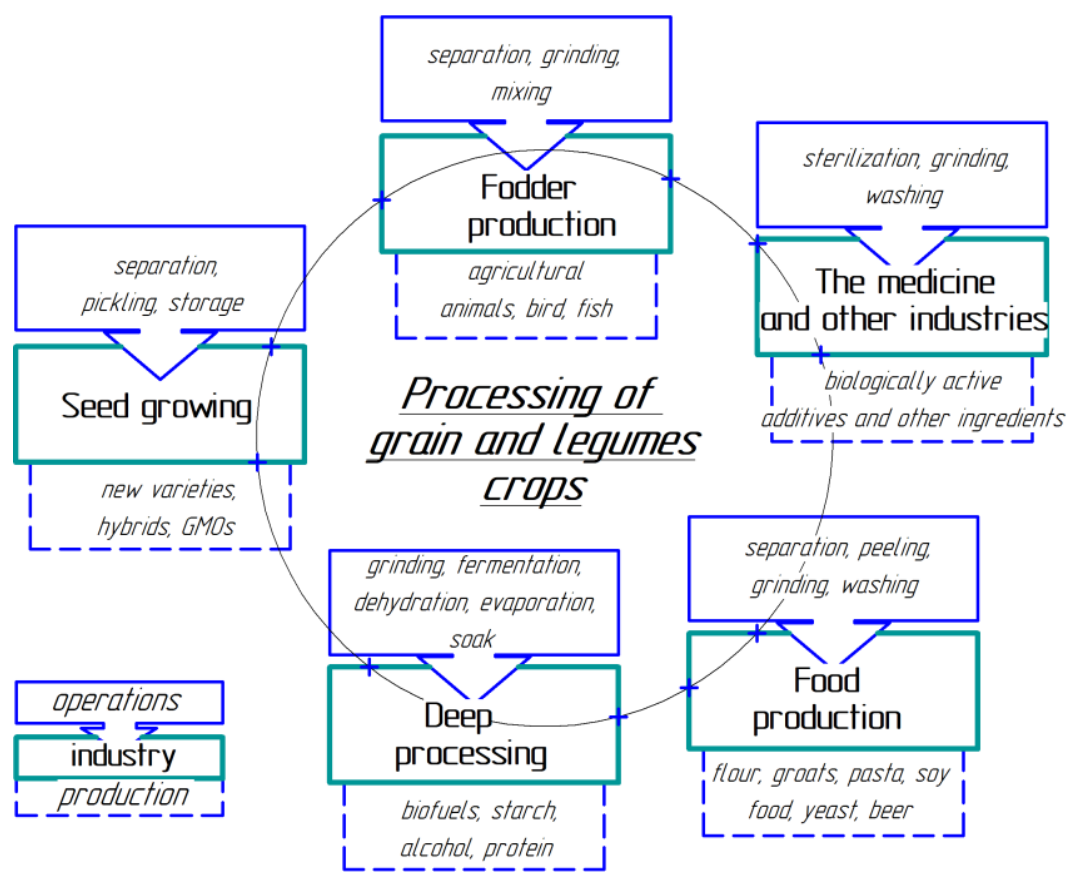

Fig. 1. Scheme of the basic operations of grain and legumes crop processing

Abrasive wear has a detrimental effect on metal work surfaces. Its peculiarity lies in the direct destruction of the surface layer, which at any given moment of time constitutes an insignificant part of the number of all contacts by abrasive particles on the surface. The most effective ways to improve the quality of the grinding process, which directly depends on the wear resistance of the working surfaces, include: organization of the optimal number of impacts of the working bodies (the less, the better); selection of alternative materials for the manufacture of working bodies; hardening of working surfaces; providing targeted and timely maintenance; carrying out operations for preliminary cleaning of grain crops.

Thus, with the wear of the working bodies of the crusher, the degree of grinding of the initial material will also change. However, in the development of theories that increase the efficiency of grinders, this factor is either not considered, or is attributed to a separate experimental study. Therefore, special attention should be paid to the processes of cleaning grain crops in lines for the preparation of feed for farm animals. Where, by analogy with the technology of deep processing and the food production, feed grain must be washed and cleaned, which will lead to a decrease in the contamination of such a mass with auxiliary trash impurities [8-10].

To find out how important these operations are in the processing of grain crops and how they affect the grinding process, we carried out a number of experimental studies.

\section{Materials and methods}

For tests on grinding grain crops, we selected varieties and types of grain that are used for the preparation of animal feed: winter wheat "Yuka" (class 3), "Tanya" (class 4), wheat of the 2nd grade, hybrid corn "Atalis", peas "Sputnik", oats "Desant", winter barley "Rubezh", corn and winter wheat substandard. The samples were investigated according to two parameters: injury of caryopses and contamination with mineral and trash impurities. All grain crops were provided by the "Kazminsky" collective farm-breeding plant of the Stavropol Territory. The collection was carried out on combines of the New Holland CX8080 brand, loading, reloading operations and storage conditions were identical for all samples.

The injury test of weighed grain samples for $2000 \mathrm{~g}$ was carried out in the laboratory of the branch of the Federal State Budgetary Institution "Rusagricultcenter" in the Stavropol Territory, and in accordance with the interstate standard 30483-97 [11]. Guided by the accepted types of seed injuries, a table was filled out according to the appropriate form with the indications: A1 - whole, A2 - slightly 
damaged, B1 - the shell is damaged, B2 - a crack in the grain, B3 - a chip in the grain, $\mathrm{C} 1$ - the embryo is damaged, $\mathrm{C} 2$ - the embryo is knocked out, $\mathrm{C} 3$ - the grain is completely destroyed.

For the study, a device is used, consisting of: a LED strip, arc enveloping a Petri dish with edges at an angle of $45^{\circ}$ and supports at opposite ends of its diameter; a mains adapter for converting the standard voltage to $12 \mathrm{~V}$ and glasses with 20x magnification. The device has two queues of examined grains taken from different samples. The sequence of the analysis: 1. Preparation of colored water. A $100 \mathrm{ml}$ flask is filled with water mixed with paint in a ratio of $2.5 \ldots 2.7 / 100$. The solution is thoroughly mixed and infused for 2 ...3 minutes. 2. Working with grains. Randomly counted 200 pcs. from each sample are poured into colored water and left for $5 . .6$ minutes. After the liquid is drained, the grains are dried on a napkin or other absorbent cloth until completely dry. After that, the grains are added to one of the queues of the device. Next, the device is connected to the electrical network, the correct operation of the LEDs is checked. Using glasses (a lens on one eye), the grains are examined with tweezers and LEDs, when they are brought to the border. The grain is carefully examined from all angles and its type of injury is determined, after which the result is recorded in the table. The analysis is carried out for 100 pieces of grains, then change the eye to re-check them (a lens on the other eye). After checking each turn, you must rest your eyes for $5 \ldots 10$ minutes. 3. The accumulated values were calculated using the data entered in the table according to the formula:

$$
V=\frac{\left(A 1_{1}+A 2_{1}\right)+\left(A 1_{2}+A 2_{2}\right)}{2},
$$

where $V$-percentage of integrity in one queue, $\%$;

$A 1_{1}, A 2_{1}$ - grains included in the group $A 1$ and $A 2$ from the first check queue;

$A 1_{2}, A 2_{3}$ - grains included in the group $A 1$ and $A 2$ from the second check queue.

The values of groups B and C are determined in a similar way. The more hundreds of grain are registered in one sample, the more accurate the percentage of calculation of their injury will be.

To determine the presence and amount of abrasive material entering the cavity of the rotary crusher in the form of mineral impurities together with the grain material, a number of experimental studies were carried out on the basis of laboratories and on the equipment of the firm "Avgust" (avgust crop protection). The national standard of the Russian Federation 54078-2010 regulates the content of various trash impurities in feed wheat. Mineral impurities according to the state standard should not exceed $1 \%$ of the total mass. Initially, using a set of sieves of different diameters $(\varnothing-4,2,1,0.5 \mathrm{~mm})$ and the collecting bottom, $100 \mathrm{~g}$ of grain crops were separated from the trash and mineral impurities in the total mass (Figure 2, a). Further, from the sifted samples, weighed portions of $50 \mathrm{~g}$ whole grains were taken (Figure 2, b). Then, by washing in a centrifuge, mineral impurities were separated from the surface of the grains. The formed precipitate was passed through filter paper, after which the samples were dried over a burner and weighed again (Figure 2, c). According to the weighing results, the formed sediment was determined for every $0.05 \mathrm{~kg}$. In accordance with the methodology, the results were recalculated for the content of mineral impurities in $1000 \mathrm{~kg}$ and in percent. [7, 12].
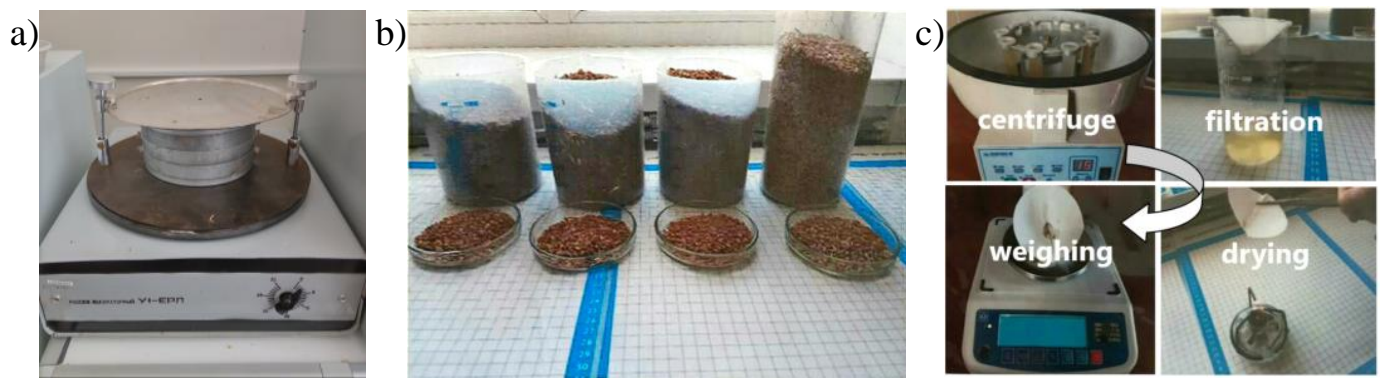

Fig. 2. Determination of the amount of mineral impurities in grain:

$\mathrm{a}$ - sieving; $\mathrm{b}$ - selection of whole grains; $\mathrm{c}$ - washing

Additionally, we carried out an experiment to simulate the process of grinding grain of durum feed wheat with different concentrations of mineral impurities in a horizontal rotary crusher, described in sufficient detail in [3]. We made counterforces from hardened Steel 45 with a hardness of $54 \mathrm{HRC}$ and applied markings every $0.5 \mathrm{~mm}$ along the bisector $\mathrm{AB}$ (Figure 3, a) for a comparative analysis of their 
wear at various concentrations $(0.4,2.9,5.4 \%)$ of mineral impurities in the form of quartz sand. Additionally, wear was recorded using an Axiovert 40 MAT metallographic microscope with programmable magnification (Figure 3, b). After reaching the limit wear of $1.5 \mathrm{~mm}$ restoration was done by milling the surface $\mathrm{AC}$ in the $\mathrm{AD}$ direction to eliminate the indicated wear and restore the shape of the counterforce with a new marking (Figure 3, a).

a)

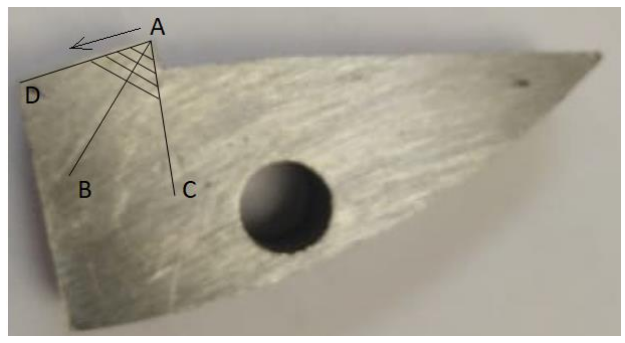

b)

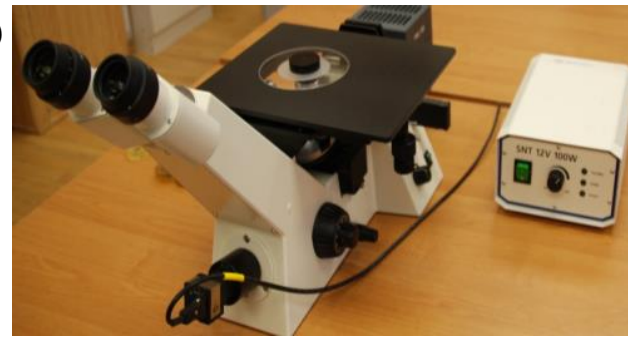

Fig. 3. Study of counterforce wear: a - markup scheme of counterforce; $\mathrm{b}$ - microscope Axiovert 40 MAT

Based on the results of the experiments, data were obtained, entered in pivot tables and graphs were built.

\section{Results and discussion}

Table 1 summarizes the aggregate average data based on the results of the study of the injury rate of grains of various crops.

Table 1

Average values of injury rate of caryopses of the studied grain crops

\begin{tabular}{|l|c|c|c|c|c|c|c|c|}
\hline \multicolumn{1}{|c|}{ Type of injury } & A1 & A2 & B1 & B2 & B3 & C1 & C2 & C3 \\
\hline Winter wheat, grade "Yuka" & $92.5 \%$ & $2.2 \%$ & $2.1 \%$ & - & - & $2 \%$ & $1.2 \%$ & - \\
\hline Oats, grade "Desant" & $96.5 \%$ & $1.5 \%$ & $0.8 \%$ & - & - & - & - & $1.2 \%$ \\
\hline Winter wheat, grade "Tanya: & $81.4 \%$ & $12.1 \%$ & $1.1 \%$ & - & $1.4 \%$ & $2.2 \%$ & $1.8 \%$ & - \\
\hline Winter barley, grade "Rubezh" & $92.3 \%$ & $3.5 \%$ & $2.9 \%$ & - & $1.3 \%$ & - & - & - \\
\hline Corn, grade "Atalis" & $75.4 \%$ & $2.8 \%$ & $5 \%$ & $6.5 \%$ & $3.1 \%$ & $4.2 \%$ & $3 \%$ & - \\
\hline Corn, substandard & $80.9 \%$ & - & $5.6 \%$ & $6.1 \%$ & - & $3.5 \%$ & - & $3.9 \%$ \\
\hline Wheat of the 2nd grade & $82.9 \%$ & $5.6 \%$ & $2 \%$ & $2.1 \%$ & - & $3.2 \%$ & $3 \%$ & $1.2 \%$ \\
\hline
\end{tabular}

Analyzing the data obtained, we can say that up to $24.6 \%$ of grains are damaged. This will lead to grinding of almost every third grain at the first contact with the working bodies and thereby overgrinding up to $30 \%$ of the total mass with the receipt of flour fractions. These fractions not only cause increased abrasive wear, but are also not suitable for feed for poultry and a number of other animals, and require additional processing. Based on this, it is possible to recommend a decrease in the number of working bodies, or the number of their impacts on the initial product in grinders working to the required granulometric composition of grain, which will save the energy and reduce the metal consumption of structures and additionally allow to reduce the amount of over-grinded flour fractions requiring additional action (pressing, mixing in aqua and others) for their application.

Trash impurities include: mineral (lumps of earth, pebbles, particles of slag, ore), organic (parts of stems, rods, awns, films, parts of leaves, etc.) and other impurities (seeds of wild and cultivated plants) [13]. In the course of sifting samples of various grain crops, data were obtained on the presence of trash and mineral impurities in the total mass (Table 2).

Table 2

Content of impurities in the mass of grain

\begin{tabular}{|l|c|c|c|}
\hline \multicolumn{1}{|c|}{ Samples } & Trash impurities, \% & Mineral impurities, \% & Total volume, \% \\
\hline Winter wheat, grade "Tanya" & 3.1 & 2.2 & 5.3 \\
\hline Winter wheat, grade "Yuka" & 2.5 & 1.9 & 4.4 \\
\hline Winter barley, grade "Rubezh" & 4.5 & 2.8 & 7.2 \\
\hline Winter wheat, substandard & 5.2 & 3.5 & 8.7 \\
\hline
\end{tabular}


In addition to the impurities present in the total mass, the smallest dust particles and other impurities can be found on the surface of the grains. The studies carried out with the washing of caryopses by centrifugation confirmed this. For the study on centrifuge of substandard wheat, like the rest of the samples, only whole caryopses were selected.

According to the weighing results, the sediment formed in the form of mineral impurities was: for wheat varieties "Tanya" and "Yuka" $-0.3 \ldots 0.4 \%$, for barley varieties "Rubezh" $-1.3 \ldots 1.8 \%$ and for substandard winter wheat $-1.6 . .2 .3 \%$. Thus, even without taking into account sifted trash impurities, wheat and barley samples contain up to $2.3 \%$ of mineral impurities on the surface of the grains. This amount may be sufficient to reduce the efficiency of the grinding process, that is, the wear of the working bodies will be further intensified due to the accumulation of over-grinded flour fractions of grains and mineral impurities in the working cavity of the crusher.

The results of modeling the grinding process of durum wheat with concentrations of mineral impurities from $0.4 \%$ to $5.4 \%$ in the mass of grain material showed that at a circumferential speed of the rotor $v=5 \mathrm{~m} / \mathrm{s}$, the wear of the Steel 45 counterforce was $0.7 \ldots 2.8 \mathrm{~mm} \cdot \mathrm{t}^{-1}$. Figure 4 shows the dependence of the volume of the grinded mass of wheat grain after two stages of restoration of the geometry of the counterforce after complete wear by $1.5 \mathrm{~mm}$ at $0.4 \%$ concentration of mineral impurities.

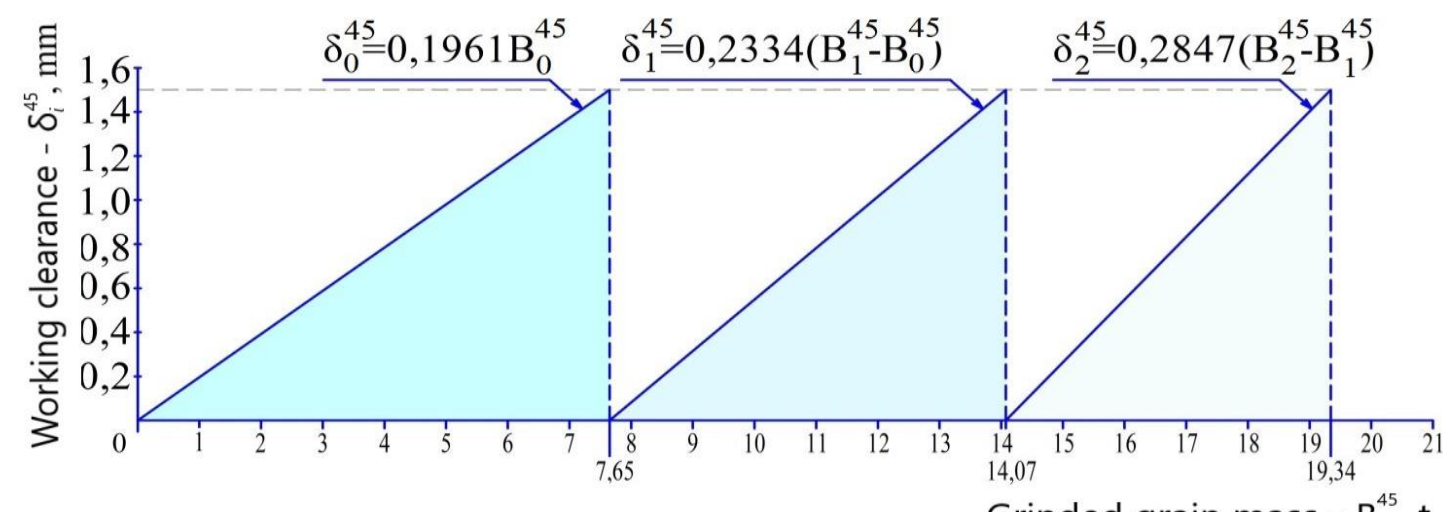

Fig. 4. Dependence of the volume of crushed wheat on the amount of counterforce wear, made of hardened Steel 45 at $0.4 \%$ concentration of abrasive

The wear rate in the first period of work of the counterforce was:

$$
\delta_{0}^{45}=0.1961 \cdot B_{0}^{45} .
$$

After restoration the worn surface, the wear rate can be determined from the equation:

$$
\delta_{1}^{45}=0.2334\left(B_{1}^{45}-B_{0}^{45}\right),
$$

where $B_{1}^{45}-$ volume of the grinded fraction after restoration of the hardened counterforce made of Steel 45, t.

After re-restoration the counterforce, the wear rate will be:

$$
\delta_{2}^{45}=0.2847\left(B_{2}^{45}-B_{1}^{45}\right),
$$

where $B_{2}^{45}-$ volume of the grinded fraction after second re-restoration for the counterforce, t.

Probably, it is possible to carry out further restoration using surfacing or similar methods, but it is more expedient to replace the counterforce with a new one due to the possibility of a more accurate setting of the working clearance without the use of shims.

The data obtained indicate that, in fact, after crushing 7.65 tons of grain, the crusher will operate in violation of the requirements for the granulometric composition of the finished product. Therefore, it is necessary to carry out timely maintenance or preliminary cleaning-washing of grain from mineral impurities to increase the durability of the working bodies. 
The results obtained speak in favour of carrying out operations for cleaning grain before its processing, as, for example, in flour production and other branches of food industry for humans $[14 ; 15]$. This will allow not only to avoid the ingress of trash, harmful and mineral impurities into food and feed, but will additionally increase the durability of the grinding equipment.

\section{Conclusions}

1. The proposed classification scheme for the main stages of grain processing makes it possible to recommend the use of washing and cleaning to increase the efficiency of the preparation of feed for agricultural animals by analogy with the production and other industries.

2. Studies have shown that every third grain in the mass of forage crops has micro and macro damage, due to which it has greater fragility. These data make it possible to modernize or create new grinders with an optimal amount of impacts on whole grains during their destruction, thereby increasing the quality of the finished product, reducing the amount of over-grinded flour fraction and the energy consumption of the process.

3. Laboratory tests on washing whole intact grains have shown that up to $2.3 \%$ of mineral impurities on their surface. Also, when sifting samples of various grain crops, up to $8.7 \%$ of the total weight were trash and mineral impurities. This amount is enough to intensively wear out the metal working bodies of the grinders. Thus, operations for preliminary cleaning of the crushed grain will increase the durability of the grinding machines and the quality of the finished product.

4. The results of grinding feed wheat showed that the wear rate of metal working bodies made of hardened Steel 45, depending on the concentration of mineral impurities in the initial mass, can vary from 0.7 to $2.8 \mathrm{~mm} \cdot \mathrm{t}^{-1}$. Thus, operations for cleaning grain crops can reduce the wear of all working surfaces in contact with the grain mass up to four times, participating in the processes of processing grain crops from reloading and transporting operations to grinding and mixing.

\section{References}

[1] Мельников С.В. Механизация и автоматизация животноводческих ферм (Mechanization and automation of livestock farms). Leningrad: Kolos, 1978, p. 560. (In Russian).

[2] Iskenderov R., Lebedev A., Zacharin A., Lebedev P. Evaluating effectiveness of grinding process grain materials. Engineering for Rural Development. Volume 17, 2018, pp. 102-108. DOI: $10.22616 /$ erdev2018.17.N147.

[3] Lebedev A., Iskenderov R., Zhevora Y. etc. Feasibility study of the grinding process of grain materials. Agronomy Research, 2020, T. 18, № 3, pp. 2117-2126. DOI: 10.15159/AR.20.191.

[4] Chkalova M., Pavlidis V. Modeling of grain raw stuff grinding process. Engineering for Rural Development, Volume 19, 2020, pp. 341-348. DOI: 10.22616/ERDev.2020.19.TF080.

[5] Iskenderov R., Lebedev A., Zacharin A., Lebedev P., Marjin N. Constructive and regime parameters of horizontal impact crusher of grain materials. IOP Conference Series: Earth and Environmental Science. 12th International Scientific Conference on Agricultural Machinery Industry, INTERAGROMASH 2019, 2019, C. 012057. DOI: 10.1088/1755-1315/403/1/012057.

[6] Müller M., Hrabě P. Overlay materials used for increasing lifetime of machine parts working under conditions of intensive abrasion. Research in Agricultural Engineering, Volume 59, Issue 1, 2013, pp. 16-22. DOI: 10.17221/64/2011-rae.

[7] Искендеров Р.Р., Лебедев А.Т., Шумский А.С. Влияние изнашивающей способности зерновых материалов на ресурс деталей роторной дробилки (Influence of the wearing capacity of grain materials on the resource of details of the rotary crushers). STATE AND PROSPECTS FOR DEVELOPMENT OF THE AGROINDUSTRIAL COMPLEX. Collection of scientific papers of the XII International Scientific and Practical Conference in the framework of the XXII Agroindustrial Forum of the South of Russia and the "Interagromash" exhibition. Don State Technical University, Agrarian Research Center "Donskoy", 2019, pp. 292-295. (In Russian).

[8] Marian Panasiewicz, Paweł Sobczak, Jacek Mazur, Kazimierz Zawiślak, Dariusz Andrejko. The technique and analysis of the process of separation and cleaning grain materials. Journal of Food Engineering, Volume 109, Issue 3, April 2012, pp. 603-608. DOI: 10.1016/j.jfoodeng.2011.10.010. 
[9] Yanhan Wu, Xiaoyu Li, Enrong Mao, Yuefeng Du, Fan Yang. Design and development of monitoring device for corn grain cleaning loss based on piezoelectric effect. Computers and Electronics in Agriculture, Volume 179, December 2020, 105793.

DOI: 10.1016/j.compag.2020.105793

[10] Jin H., Hu S., Xie B., Yan Y., Yang M., Zhou F.. Experimental optimization for cleaning parameters and field application of cartridge filter in bulk grain loading. Powder Technology, Volume 378, Part A, 22 January 2021, pp. 421-429. DOI: 10.1016/j.powtec.2020.10.003

[11]ГОСТ 30483-97 Зерно. Методы определения общего и фракционного содержания сорной и зерновой примесей; содержания мелких зерен и крупности содержания зерен пшеницы, поврежденных клопом-черепашкой; содержание металломагнитной примеси. (Interstate standard. Grain. Methods for determination of general and fractional content of extraneous matter and damaged grains; content of small grains and grain size; content of grains attacked by pests; content of metallic particles). (In Russian).

[12] ГОСТ 54078-2010 Пшеница кормовая. Технические условия (National standard of the Russian Federation. Fodder wheat. Technical conditions). (In Russian).

[13] Angelovic M., Krištof K., Angelovic M., Jobbágy, J. The effect of post-harvest processing in model line at food maize grains external and internal quality. TAE 2019 - Proceeding of 7th International Conference on Trends in Agricultural Engineering 2019, 2019, pp. 32-39.

[14] Hill V. Industry regulation of quality in bread, flour and wheat in France and the U.S. Book Chapter. Contributions to Management Science, 2014, pp. 83-121. DOI: 10.1007/978-3-319-04250-3_3.

[15] Brera C., Peduto A., Debegnach F. etc. Study of the influence of the milling process on the distribution of deoxynivalenol content from the caryopsis to cooked pasta. Food Control, Volume 32, Issue 1, July 2013, pp. 309-312. DOI: 10.1016/j.foodcont.2012.12.005. 